CINQUINI FILHO, J. et al. Desempenho econômico do sistema de produção de cria, recria e engorda em bovinos de corte da Fazenda Rosário, Ituiutaba-MG. PUBVET, Londrina, V. 5, N. 9, Ed. 156, Art. 1056, 2011.

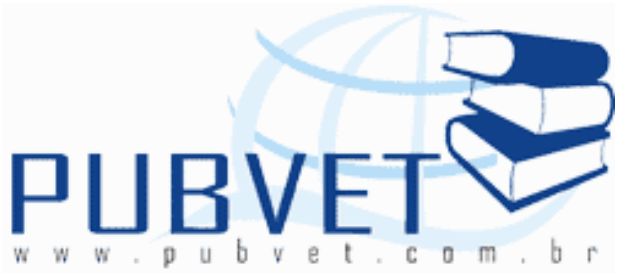

PUBVET, Publicações em Medicina Veterinária e Zootecnia.

\title{
Desempenho econômico do sistema de produção de cria, recria e engorda em bovinos de corte da Fazenda Rosário, Ituiutaba-MG
}

João Cinquini Filho ${ }^{*}$, Mariela Silva Moura ${ }^{2}$, Rafael Silveira Carreon ${ }^{1}$, Adriano Pirtouscheg ${ }^{3}$

${ }^{1}$ Médico Veterinário.

${ }^{2}$ Graduanda em Medicina Veterinária, Universidade Federal de Uberlândia. Uberlândia, MG.

${ }^{3}$ Docente da Faculdade de Medicina Veterinária, Universidade Federal de Uberlândia. Uberlândia, MG.

*Autor para correspondência: Rua Ceará, s/n, Bloco 2D, CEP 38400-902, Uberlândia, MG, Brasil. E-mail: joaocinquini@hotmail.com

\section{Resumo}

A pecuária de corte brasileira apresenta baixos índices de produtividade, razão pela qual, seu potencial de expansão é bastante grande. É necessário que novas tecnologias acompanhadas de técnicas de produção estejam inseridas num contexto mais amplo que atenda o conjunto da fazenda. O planejamento produtivo e o levantamento dos gastos gerado numa propriedade auxiliam na busca de resultados positivos. O presente projeto teve como objetivo a análise de desempenho técnico e econômico do sistema de produção de cria-recriaengorda de gado de corte na fazenda Rosário, município de Ituiutaba - MG. A implementação da escrituração zootécnica esta sendo importante para a 
CINQUINI FILHO, J. et al. Desempenho econômico do sistema de produção de cria, recria e engorda em bovinos de corte da Fazenda Rosário, Ituiutaba-MG. PUBVET, Londrina, V. 5, N. 9, Ed. 156, Art. 1056, 2011.

propriedade, pois viabilizou a análise de alguns índices produtivos e reprodutivos importantes para o crescimento da atividade, da mesma forma que a escrituração financeira fez com que o produtor saiba onde estão os pontos de estrangulamento de sua produção e possa cortar custos, e até melhorar os investimentos na propriedade.

Palavras-chave: Análise de desempenho, Escrituração zootécnica, Escrituração financeira.

\title{
Economic performance of the production system creates and fattening in beef cattle farm Rosario Ituiutaba-MG
}

\begin{abstract}
The Brazilian beef cattle shows low levels of productivity that is why, their potential for expansion is large. It is necessary that new technologies in combination with techniques of production be incorporated into a broader context that addresses the whole farm. The planning of production and removal expenses generated on a property in helps in the search of results. This project aimed to the analysis of technical performance and economic system of production of creation, re-creation and fattening of beef cattle farm in Rosario, Ituiutaba municipality - MG. The implementation of the livestock keeping is important for the property, as allowed the analysis of some productive and reproductive important indices to the growth of activity in the same way that the financial bookkeeping led the producer knows where are the bottlenecks in their production and to cut costs and to improve investment in property.
\end{abstract}

Keywords: Performance Review, Bookkeeping zootechnical, Bookkeeping financial.

\section{Introdução}

O Brasil possui o segundo maior rebanho bovino mundial, sendo o maior rebanho comercial do mundo, já que a Índia, líder mundial em rebanho bovino, 
CINQUINI FILHO, J. et al. Desempenho econômico do sistema de produção de cria, recria e engorda em bovinos de corte da Fazenda Rosário, Ituiutaba-MG. PUBVET, Londrina, V. 5, N. 9, Ed. 156, Art. 1056, 2011.

não possui exploração bovina comercial apresentando baixas taxas zootécnicas e volume de abate.

A pecuária de corte brasileira está em constante avanço, com novas pesquisas, tecnologias e técnicas, que estão disponíveis aos produtores, e que, visam o máximo desempenho da propriedade. Isto significa também maiores lucros ao produtor, e ainda a satisfação do mercado consumidor.

A economia brasileira tem passado por rápidas transformações nos últimos anos. Neste contexto ganham espaço novas concepções, ações e atitudes, em que produtividade, custo e eficiência se impõem como regras básicas de sobrevivência em um mercado cada vez mais competitivo e globalizado (IEL, SEBRAE, CNA, 2000).

A pecuária bovina de corte possui grande significância dentro do ambiente sócio-econômico brasileiro, é uma atividade desenvolvida na quase totalidade dos municípios brasileiros, como uma ampla variedade de raças, sistemas de produção, índices de produtividade, condições sanitárias e sistemas de comercialização, de acordo com as peculiaridades e exigências de cada região e do mercado que se destina.

Os produtores recebem, com freqüência, enorme quantidade de recomendações para intensificação da bovinocultura de corte, no Brasil, por meio de revistas especializadas, jornais, técnicos, programas de televisão, livros, vendedores, internet, porém na maioria das vezes, têm dificuldade em selecionar as informações que possam realmente alavancar sua rentabilidade (ALVES E MORAES, 2008).

Segundo Polaquini (2006) desde a fase inicial da modernização da pecuária de corte que ocorreu em meados da década de 70, com a implantação de programas de crédito subsidiados até dias atuais que apresentam redução na margem de lucro da atividade pecuária de corte, com competitividade, globalização dos mercados, dentre outros fatores, exige do produtor a busca de meios para se adequar à realidade econômica e planejar a atividade. $O$ primeiro passo a ser tomado são os registros zootécnicos ou 
CINQUINI FILHO, J. et al. Desempenho econômico do sistema de produção de cria, recria e engorda em bovinos de corte da Fazenda Rosário, Ituiutaba-MG. PUBVET, Londrina, V. 5, N. 9, Ed. 156, Art. 1056, 2011.

escrituração zootécnica que constituem o instrumento fundamental para que o produtor dimensione a eficiência técnica do sistema e identifique os pontos de estrangulamento.

Segundo Santos \& Marion (1996), "pecuária é a arte de criar e tratar o gado. Há dois tipos de produção: extensiva (gado criado solto, sem alimentação suplementar, ocupando grande área territorial com um baixo rendimento) e a intensiva (quando o gado é criado confinado, com alimentação a base de suplemento, aumentando o seu ganho de peso, sua rentabilidade buscando um aprimoramento técnico e também suprindo períodos de secas)".

De acordo com Marion (2001), os sistemas de custos têm como objetivos: auxiliar a administração na organização e controle da unidade de produção, revelando ao administrador as atividades de menor custo, as mais lucrativas, as operações de maior e menor custo e as vantagens de substituir umas pelas outras; permitir uma correta valorização dos estoques para apuração dos resultados obtidos em cada cultivo ou criação; oferecer bases consistentes e confiáveis para projeção dos resultados e auxiliar o processo de planejamento rural, principalmente quando o administrador precisa decidir o que, quando e como plantar, e orientar os órgãos públicos e privados na fixação de medidas, como garantia de preços mínimos, incentivo à produção de determinado produto em escala desejada, estabelecimento de limites de crédito etc.

A gestão empresarial (planejamento, organização, direção e controle) é uma ferramenta do processo administrativo para aumentar a competitividade do sistema.

O planejamento técnico e econômico de uma fazenda visa projetar uma meta de produção, especificada, orientando e pré determinando passos a serem seguidos levando ao objetivo determinado no começo do projeto.

Diante da gama de informações originadas pela contabilidade de custos pode-se destacar a função de escolher o tipo de produção a adotar, o custo fixo, o lucro e a margem de contribuição, estabelecendo os limites de 
CINQUINI FILHO, J. et al. Desempenho econômico do sistema de produção de cria, recria e engorda em bovinos de corte da Fazenda Rosário, Ituiutaba-MG. PUBVET, Londrina, V. 5, N. 9, Ed. 156, Art. 1056, 2011.

capacidade de produção. Utilizando-se do conceito de ponto de equilíbrio, ao mensurar o retorno sobre investimento, a fixação de um preço de venda, e a decisão entre comprar ou produzir, a empresa estará operando literalmente com custos.

A escrituração financeira é outra ferramenta utilizada juntamente à escrituração zootécnica que propõem uma rotina diária de coleta de dados. Os principais dados a serem levantados: são o inventário, e os custos de produção, como por exemplo, gastos com alimentação, mão-de-obra, medicamento, combustível etc. Através dos resultados obtidos na escrituração financeira fica mais fácil planejar novos investimentos e também ter controle dos gastos da propriedade.

A utilização da escrituração financeira visa melhor acompanhamento dos gastos da propriedade, e isto faz com que o produtor saiba se sua atividade realmente está lhe oferecendo o lucro esperado. Pois com o corte de gastos supérfluos sobrará caixa para investimentos e melhorias na propriedade.

A escrituração zootécnica pode ser realizada manualmente ou com auxilio de programas de computador usando planilhas em Excel $\AA$, ou com a utilização de softwares específicos para a tarefa.

O objetivo do presente trabalho foi analisar economicamente o processo de produção de cria-recria e engorda de gado de corte na fazenda Rosário no município de Ituiutaba - MG onde esta propriedade fora recebida de herança familiar a apenas 2 anos, e consta de instalações e construções novas ou que ainda estão em processo de acabamento. Este trabalho obteve o cálculo dos custos de produção, gestão dos custos, avaliação financeira, planejamento financeiro e a aplicação dos conceitos. Com a finalidade de fornecer uma visão geral da propriedade tanto dos gastos totais como do desempenho do rebanho. 
CINQUINI FILHO, J. et al. Desempenho econômico do sistema de produção de cria, recria e engorda em bovinos de corte da Fazenda Rosário, Ituiutaba-MG. PUBVET, Londrina, V. 5, N. 9, Ed. 156, Art. 1056, 2011.

\section{Material e métodos}

A análise foi desenvolvida no sistema de cria-recria e engorda de gado de corte da fazenda Rosário, no município de Ituiutaba - MG.

Os dados foram coletados no período de 01 de Agosto de 2008 a 20 de Maio de 2009, pelo proprietário, e ainda pelo executor do projeto. Todos os dados foram armazenados em tabelas de WORD $\AA$, sendo que os dados financeiros foram transferidos para planilhas de EXCEL $®$ e posteriormente analisados através de alguns índices financeiros.

Ao nascer cada animal entra na lista de animais da propriedade e são brincados a fim de controle e identificação, e quando morrem ou vendidos são excluídos da mesma e retirados os brincos de controle. Esta lista de animais da propriedade é conferida mensalmente a fim de analisar as movimentações nos estoques de animais na propriedade para saber se há superveniência (crescimento do rebanho) ou insubsistência (decréscimo do rebanho).

O modelo adotado para realização da análise de desempenho econômico segue os passos e os procedimentos habituais que devem constar num trabalho cientifico (REIS \& GUIMARÂES, 1986; PIRTOUSCHEG 1999), onde os custos foram divididos em variáveis e fixos e os mesmos subdivididos em operacionais e alternativos.

Sendo considerado como custo fixo: depreciação de construções e benfeitorias, de máquinas e equipamentos, de matrizes e reprodutores, de animais de trabalho, de pastagens. E considerando custo variável: os insumos de modo geral; aluguel de máquinas e equipamentos; combustíveis e lubrificantes; animais de recria e engorda; mão de obra temporária; impostos e taxas variáveis. Foi usado o seguinte calculo: Custo Total $=$ Custo Fixo + Custo Variável $\rightarrow \mathrm{CT}=\mathrm{CF}+\mathrm{CV}$ e Custo Operacional Total $=$ Custo Operacional Fixo + Custo Operacional Variável $\rightarrow$ CopT $=$ CopF + CopV.

Os custos operacionais variáveis foram obtidos através da análise dos gastos com alimentação do rebanho, mão-de-obra, medicamentos, combustível, manutenção das pastagens, impostos e taxas, e gastos diversos 
CINQUINI FILHO, J. et al. Desempenho econômico do sistema de produção de cria, recria e engorda em bovinos de corte da Fazenda Rosário, Ituiutaba-MG. PUBVET, Londrina, V. 5, N. 9, Ed. 156, Art. 1056, 2011.

(telefone e outros), todos os dados foram armazenados em tabelas e arquivados para as análises.

Para o cálculo das depreciações utilizou-se o método linear, considerando neste trabalho um valor residual de $10 \%$ do valor atual.

De acordo com Pirtouscheg (1999) em rebanhos auto renovados, não se determina sua depreciação, devido o mesmo ser substituído por animais oriundos do próprio rebanho, portanto não se calculou a depreciação das matrizes. Porém animais oriundos de outras propriedades constam de depreciação.

Os cálculos foram feitos a partir da metade do valor do custo operacional variável multiplicado por uma taxa de juros de $6 \%$ ao ano, estabelecida para o presente trabalho.

A remuneração do capital de máquinas, equipamentos, construções, benfeitorias e dos animais foi calculado com taxa de juros de $6 \%$ para 0 período de analise do trabalho.

A remuneração da terra foi calculada estipulando um valor de aluguel de pasto.

Para se calcular a depreciação considera a relação entre o valor do bem e seu período de vida útil provável, podendo deduzir-se, caso necessário do valor atual um valor final ou residual presumido. Foi usado o método linear e descontado o valor residual para máquinas e equipamentos.

O lucro foi obtido da receita vinda com a venda dos animais e arrendamento da terra.

A equivalência em preço foi calculada pela formula seguinte: $\mathrm{Pu}=$ RPp/QPp, em que: Pu = Preço unitário; RPp = Receita do Produto Principal; QPp: Quantidade Produto Principal.

O ponto de nivelamento (PN) foi determinado com base no custo fixo total (CFT), no custo variável total unitário (CVTu) e no preço unitário (Pu) do produto, segundo a fórmula: $\mathrm{PN}=\mathrm{CFT} /(\mathrm{Pu}-\mathrm{CVTu})$. 
CINQUINI FILHO, J. et al. Desempenho econômico do sistema de produção de cria, recria e engorda em bovinos de corte da Fazenda Rosário, Ituiutaba-MG. PUBVET, Londrina, V. 5, N. 9, Ed. 156, Art. 1056, 2011.

A lucratividade foi avaliada segundo a fórmula: Lucratividade $=\{$ (Renda bruta total - Custo Total ) x 100\} / Renda bruta total.

A rentabilidade foi avaliada segundo a fórmula: Rentabilidade sobre o capital $=($ Lucro/Capital Total) $\times 100$.

A capacidade de investimento foi avaliada segundo a fórmula: Capacidade de Investimento $(\mathrm{CI})=$ Renda Bruta - Custo Operacional total.

$O$ índice de capacidade de investimento foi avaliado segundo a fórmula: Índice de capacidade de investimento $=(\mathrm{CI} /$ Renda Bruta $) \times 100$.

\section{Resultados}

\section{Processo de Produção}

A fazenda dispõe de animais de todas as faixas etárias e sexos. Os animais foram mantidos somente a pasto, Brachiaria brizantha cv. Toledo, e com suplementação mineral à vontade no cocho. Sendo suplementados no período da seca com sal mineral proteinado. Os animais foram mantidos extensivamente sem estação de monta definida.

Ao nascimento, os bezerros foram submetidos ao controle sanitário, com corte e desinfecção do umbigo, vacinação contra febre aftosa que segue a orientação do Instituto Mineiro de Agropecuária. As fêmeas foram vacinadas contra brucelose por ocasião da desmama em dose única.

A vermifugação nos bezerros foi efetuada mensalmente e nos demais animais foi realizada uma vermifugação estratégica feita três vezes ao ano, nos meses de maio, julho e setembro, e conforme o necessário foi realizado o controle de ectoparasitas. 
CINQUINI FILHO, J. et al. Desempenho econômico do sistema de produção de cria, recria e engorda em bovinos de corte da Fazenda Rosário, Ituiutaba-MG. PUBVET, Londrina, V. 5, N. 9, Ed. 156, Art. 1056, 2011.

\section{Área}

Tabela 1 - Uso atual e valor das terras da Fazenda Rosário, no período de 08 de Agosto de 2008 a 30 de Abril de 2009

\begin{tabular}{lll}
\hline Descrição & $\begin{array}{l}\text { Área } \\
\text { (ha) }\end{array}$ & Valor (R\$) \\
\hline Pastagens & 170 & $442.000,00$ \\
Reserva & 75 & $195.000,00$ \\
Benfeitorias & 15 & $39.000,00$ \\
Total & 260 & $676.000,00$ \\
\hline $\begin{array}{l}\text { Remuneração } \\
\text { terra }\end{array}$ & & $\mathbf{1 0 . 6 0 0 , 0 0}$ \\
\hline
\end{tabular}

Fonte: Dados da pesquisa

\section{Ficha de Conferência do rebanho}

Tabela 2 - Ficha de Conferência do rebanho da Fazenda Rosário, município de Ituiutaba, no mês de Abril de 2009.

\begin{tabular}{|c|c|c|c|c|c|c|c|}
\hline \multirow[b]{2}{*}{ Categoria } & \multirow{2}{*}{$\begin{array}{c}\text { Existência } \\
\text { Anterior } \\
10 / 04 / 09\end{array}$} & \multicolumn{2}{|c|}{ Entradas } & \multicolumn{2}{|c|}{ Saídas } & \multirow{2}{*}{$\begin{array}{c}\text { Mudança } \\
\text { de } \\
\text { categoria }\end{array}$} & \multirow{2}{*}{$\begin{array}{c}\text { Existência } \\
\text { atual } \\
30 / 04 / 09\end{array}$} \\
\hline & & $\begin{array}{l}\text { Nasci- } \\
\text { mentos }\end{array}$ & Compras & Mortes & Vendas & & \\
\hline Vacas & 24 & - & - & - & - & - & 24 \\
\hline $\begin{array}{l}\text { Novilhas } \\
2-3 \text { anos }\end{array}$ & 22 & - & - & - & - & - & 22 \\
\hline $\begin{array}{l}\text { Novilhas } \\
\text { 1-2 anos }\end{array}$ & 10 & - & - & - & - & - & 10 \\
\hline \multirow{2}{*}{$\begin{array}{l}\text { Bezerros } \\
\text { (as) } \\
\text { (-1 ano) }\end{array}$} & 104 & - & - & 01 & - & - & 103 \\
\hline & 07 & 01 & - & - & - & - & 08 \\
\hline $\begin{array}{l}\text { Machos } \\
\text { 1-2 anos }\end{array}$ & 20 & - & - & - & - & - & 20 \\
\hline $\begin{array}{l}\text { Machos } \\
\text { 2-3 anos }\end{array}$ & - & - & - & - & - & - & - \\
\hline $\begin{array}{l}\text { Machos + } \\
3 \text { anos }\end{array}$ & - & - & - & - & - & - & - \\
\hline Touros & 02 & - & - & - & - & - & 02 \\
\hline Total & 189 & 01 & - & 01 & - & - & 189 \\
\hline
\end{tabular}

Fonte: Dados da pesquisa 
CINQUINI FILHO, J. et al. Desempenho econômico do sistema de produção de cria, recria e engorda em bovinos de corte da Fazenda Rosário, Ituiutaba-MG. PUBVET, Londrina, V. 5, N. 9, Ed. 156, Art. 1056, 2011.

\section{Escrituração financeira}

\section{Ficha de controle de gastos mensais}

Tabela 3 - Gastos mensais da Fazenda Rosário no período de Agosto de 2008 a Abril de 2009

\begin{tabular}{c|c|c|c|c|c|c|c|c|c|r} 
Descrição & Ago. & Set. & Out. & Nov. & Des. & Jan. & Fev. & Mar. & Abr. & Total \\
\hline $\begin{array}{c}\text { Alimentação do } \\
\text { Rebanho }\end{array}$ & 1.120 & 698 & 545 & 904 & 759 & 711 & 806 & 715 & 1940 & $\mathbf{8 . 1 9 8 , 0 0}$ \\
\hline $\begin{array}{c}\text { Mão-de-obra } \\
\text { temporária }\end{array}$ & 100 & 100 & 100 & 100 & 100 & 100 & 100 & 100 & 100 & $\mathbf{9 0 0 , 0 0}$ \\
\hline Telefone & 50 & 50 & 50 & 50 & 50 & 50 & 50 & 50 & 50 & $\mathbf{4 5 0 , 0 0}$ \\
\hline Gasolina & 120 & 120 & 100 & 100 & 40 & 60 & 100 & 120 & 120 & $\mathbf{8 8 0 , 0 0}$ \\
\hline Diesel & 300 & 300 & 200 & & & & & & & $\mathbf{8 0 0 , 0 0}$ \\
\hline Sal mineral & & & 545 & 904 & 759 & 711 & 806 & 715 & & $\mathbf{4 . 4 4 0 , 0 0}$ \\
\hline Sal proteinado & 1120 & 698 & & & & & & & 1940 & $\mathbf{3 . 7 5 8 , 0 0}$ \\
\hline Vacinas & & 500 & 200 & & & & & 600 & 240 & $\mathbf{1 . 5 4 0 , 0 0}$ \\
\hline Medicamentos & 260 & 360 & 260 & 260 & 260 & 260 & 260 & 260 & 260 & $\mathbf{2 . 4 4 0 , 0 0}$ \\
\hline Taxas/ Impostos & & & 500 & & & & 200 & & & $\mathbf{7 0 0 , 0 0}$ \\
\hline Fretes & 200 & 2000 & 2000 & & & 200 & & & & $\mathbf{4 . 4 0 0 , 0 0}$ \\
\hline Manut Máquinas & & 200 & & & 50 & & & & & $\mathbf{2 5 0 , 0 0}$ \\
\hline Manut Inst. & & & 200 & & & & & & & $\mathbf{2 0 0 , 0 0}$ \\
\hline Manutenção de \\
pastagens
\end{tabular}

Fonte: Dados da pesquisa

\section{Análise Econômica}

\section{Componentes da Receita, Capital Fixo e Circulante}

A receita da propriedade é composta pela venda de animais e diversas categorias etárias, como: matrizes, novilhas, bezerros e gado de terminação. 
CINQUINI FILHO, J. et al. Desempenho econômico do sistema de produção de cria, recria e engorda em bovinos de corte da Fazenda Rosário, Ituiutaba-MG. PUBVET, Londrina, V. 5, N. 9, Ed. 156, Art. 1056, 2011.

Tabela 4 - Registro de produção da Fazenda Rosario, no período de 08 de Agosto de 2008 a 30 de Abril de 2009

\begin{tabular}{lccc}
\hline \multicolumn{1}{c}{ Produto } & $\begin{array}{c}\text { Produção } \\
\text { Vendida }\end{array}$ & $\begin{array}{c}\text { Valor unitário } \\
(\mathbf{R} \mathbf{\$})\end{array}$ & $\begin{array}{c}\text { Valor Total } \\
(\mathbf{R} \mathbf{)})\end{array}$ \\
\hline Matrizes p/ descarte & 8 & $1.500,00$ & $12.000,00$ \\
Novilhas 2-3 anos & 24 & 650,00 & $15.600,00$ \\
Bezerros até 12 & 24 & 600,00 & $14.400,00$ \\
meses & & & \\
Bezerras até 12 & 14 & 400,00 & $5.600,00$ \\
meses & 1 & $1.500,00$ & $1.500,00$ \\
Touro & 40 & $1.259,85$ & $50.394,00$ \\
Garrote 2-3 & & & \\
\hline \multicolumn{1}{c}{ Total } & $\mathbf{1 1 1}$ & & $\mathbf{9 9 . 4 9 4 , 0 0}$ \\
\hline
\end{tabular}

Fonte: Dados da pesquisa

\section{Diferença de inventário}

Tabela 5 - Diferença de inventário da Fazenda Rosário, no período de 08 de Agosto de 2008 a 30 de Abril de 2009

\begin{tabular}{|c|c|c|c|c|c|c|c|c|c|c|c|c|}
\hline \multirow{2}{*}{$\begin{array}{c}\text { Especificação } \\
\text { Categoria }\end{array}$} & \multicolumn{2}{|c|}{ Rebanho Inicial } & \multicolumn{3}{|c|}{ Entradas } & \multicolumn{3}{|c|}{ Saídas } & \multicolumn{2}{|c|}{ Estoque final } & \multicolumn{2}{|c|}{$\begin{array}{c}\text { Variação do } \\
\text { estoque }\end{array}$} \\
\hline & Qt & $\begin{array}{l}\text { Valor } \\
\text { Total } \\
(\mathbf{R} \$)\end{array}$ & $\begin{array}{l}\text { ن } \\
\text { O } \\
\text { Z }\end{array}$ & $\begin{array}{l}\text { Mudan. } \\
\text { Categ. } \\
(+)\end{array}$ & $\begin{array}{l}n \\
\text { to } \\
\text { है } \\
\text { ह่ } \\
\end{array}$ & $\stackrel{0}{ \pm}$ & $\begin{array}{c}\text { Muda } \\
\text { n. } \\
\text { Categ } \\
\text { ( - ) }\end{array}$ & 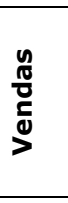 & Qt & $\begin{array}{c}\text { Valor total } \\
\text { (R\$) }\end{array}$ & Qt & $\begin{array}{l}\text { Valor Total } \\
\text { (R\$) }\end{array}$ \\
\hline Vacas com cria & 05 & $7.500,00$ & 0 & 0 & 27 & 0 & 0 & 08 & 24 & $36.000,00$ & 19 & $28.500,00$ \\
\hline $\begin{array}{c}\text { Novilhas } 2-3 \\
\text { anos }\end{array}$ & 46 & $29.900,00$ & 0 & 0 & 0 & 0 & 0 & 24 & 22 & $14.300,00$ & -24 & $-15.600,00$ \\
\hline $\begin{array}{l}\text { Novilhas 1-2 } \\
\text { anos }\end{array}$ & 0 & 0 & 0 & 10 & 0 & 0 & 0 & 0 & 10 & $6.000,00$ & 10 & $6.000,00$ \\
\hline $\begin{array}{c}\text { Bezerros } \\
\text { desmamado }\end{array}$ & 0 & 0 & 0 & 119 & 0 & 0 & 0 & 24 & 95 & $57.000,00$ & 95 & $57.000,00$ \\
\hline $\begin{array}{c}\text { Bezerras } \\
\text { desmamada }\end{array}$ & 10 & $4.000,00$ & 0 & 03 & 18 & 01 & 10 & 14 & 06 & $2.400,00$ & -04 & $-1.600,00$ \\
\hline $\begin{array}{c}\text { Bezerros até } 7 \\
\text { meses }\end{array}$ & 03 & 900,00 & 09 & 0 & 147 & 31 & 119 & 0 & 09 & $2.700,00$ & 06 & $1.800,00$ \\
\hline $\begin{array}{c}\text { Bezerras até } 7 \\
\text { meses }\end{array}$ & 03 & $1.200,00$ & 02 & 0 & 0 & 0 & 03 & 0 & 02 & 800,00 & -01 & $-400,00$ \\
\hline $\begin{array}{c}\text { Machos 1-2 } \\
\text { anos }\end{array}$ & 40 & $32.000,00$ & 0 & 0 & 20 & 0 & 40 & 0 & 20 & $16.000,00$ & -20 & $-16.000,00$ \\
\hline $\begin{array}{c}\text { Machos 2-3 } \\
\text { anos }\end{array}$ & 0 & 0 & 0 & 40 & 0 & 0 & 0 & 40 & 0 & 0 & 0 & 0 \\
\hline Bois & 02 & $3.000,00$ & 0 & 0 & 01 & 0 & 0 & 01 & 02 & $3.000,00$ & 0 & 0 \\
\hline Equinos & 15 & $37.500,00$ & 0 & 0 & 0 & 0 & 0 & 0 & 15 & $37.500,00$ & 0 & 0 \\
\hline Total & 124 & $\begin{array}{c}116.000,0 \\
0\end{array}$ & 11 & 172 & 213 & 32 & 172 & 111 & 205 & $175.700,00$ & 81 & $59.700,00$ \\
\hline $\begin{array}{c}\text { Remuneração } \\
\text { do capital }\end{array}$ & & & & & & & & & & $10.542,00$ & & \\
\hline
\end{tabular}

Fonte: Dados da pesquisa 
CINQUINI FILHO, J. et al. Desempenho econômico do sistema de produção de cria, recria e engorda em bovinos de corte da Fazenda Rosário, Ituiutaba-MG. PUBVET, Londrina, V. 5, N.

9, Ed. 156, Art. 1056, 2011.

\section{Equivalência em Preço}

Através dos dados da pesquisa tem-se:

$\mathrm{Pu}=99.494,00 / 111$ animais

$\mathrm{Pu}=\mathrm{R} \$ 896,35$

O equivalente do preço da diferença de inventário:

$\mathrm{Pu}=59.700,00 / 111$ animais

$\mathrm{Pu}=\mathrm{R} \$ 537,84$

O equivalente de preço total é a soma dos preços unitários equivalentes.

Put $=$ Soma dos Preços Unitários

Put $=896,35+537,84=R \$ 1.434,19$

Tabela 6 - Renda obtida na Fazenda Rosário, no período de 08 de Agosto de 2008 a 30 de Abril de 2009

\begin{tabular}{|c|c|c|c|}
\hline Especificação & Valor Total & Valor Unitário & \% Receita \\
\hline $\begin{array}{l}\text { Diferença de } \\
\text { Inventário }\end{array}$ & $59.700,00$ & 537,84 & 31,23 \\
\hline Venda de Animais & $99.494,00$ & 986,35 & 68,77 \\
\hline Renda Bruta & $159.194,00$ & 1434,19 & 100 \\
\hline
\end{tabular}

Fonte: Dados da Pesquisa

\section{Depreciações}

Quadro 1 - Depreciação das construções e instalações da Fazenda Rosário, no período de 08 de Agosto de 2008 a 30 de Abril de 2009

\begin{tabular}{|c|c|c|c|c|c|c|c|}
\hline Especificação & No/dimensão & Quant. & $\begin{array}{c}\text { Ano de } \\
\text { Const. }\end{array}$ & $\begin{array}{c}\text { Vida } \\
\text { Útil }\end{array}$ & Valor Atual & Idade & $\begin{array}{c}\text { Depreciação } \\
\text { anual }\end{array}$ \\
\hline $\begin{array}{c}\text { Currais de } \\
\text { manejo }\end{array}$ & $22 \times 22$ & 01 & 2007 & 30 & $38.000,00$ & 02 & $1.267,00$ \\
\hline Represa & & 01 & 2007 & 30 & $6.000,00$ & 02 & 200,00 \\
\hline Cercas & 3.100 & $\ldots$ & 2007 & 10 & $30.000,00$ & 02 & $3.000,00$ \\
\hline Casa - Peão & & 01 & 2007 & 30 & $10.000,00$ & 02 & 333,33 \\
\hline Total & & & & & $\mathbf{8 4 . 0 0 0 , 0 0}$ & & $\mathbf{4 . 8 0 0 , 3 3}$ \\
\hline $\begin{array}{c}\text { Remuneração } \\
\text { do Capital }\end{array}$ & & & & $\mathbf{5 . 0 4 0 , 0 0}$ & & \\
\hline
\end{tabular}

Fonte: Dados da Pesquisa 
CINQUINI FILHO, J. et al. Desempenho econômico do sistema de produção de cria, recria e engorda em bovinos de corte da Fazenda Rosário, Ituiutaba-MG. PUBVET, Londrina, V. 5, N. 9, Ed. 156, Art. 1056, 2011.

Quadro 2 - Depreciação das máquinas e equipamentos da Fazenda Rosário, no período de 08 de Agosto de 2008 a 30 de Abril de 2009.

\begin{tabular}{|c|c|c|c|c|c|c|c|c|}
\hline $\begin{array}{c}\text { Especifica- } \\
\text { ção }\end{array}$ & $\begin{array}{c}\mathbf{N}^{\circ} \text {. } \\
\text { HP }\end{array}$ & Quant. & $\begin{array}{c}\text { Ano de } \\
\text { Fabric. }\end{array}$ & $\begin{array}{c}\text { Vida } \\
\text { Útil }\end{array}$ & Valor Atual & $\begin{array}{c}\text { Valor } \\
\text { Residual }\end{array}$ & $\begin{array}{c}\text { Idade } \\
\text { Depreciação } \\
\text { anual }\end{array}$ \\
\hline Trator & $75 \mathrm{HP}$ & 01 & 1993 & 20 & $80.000,00$ & 8000,00 & 16 & $3.600,00$ \\
\hline Caixa d'gua & $\begin{array}{c}10.000 \\
\mathrm{~L}\end{array}$ & 01 & 2007 & 20 & $4.000,00$ & 400,00 & 02 & 180,00 \\
\hline Arado & & 01 & 1993 & 10 & $2.000,00$ & 200,00 & 16 & 180,00 \\
\hline Grade & & 01 & 1988 & 10 & $15.000,00$ & 1500,00 & 20 & $1.350,00$ \\
\hline Plantadeira & & 01 & & 10 & $4.000,00$ & 400,00 & & 360,00 \\
\hline Cultivador & & 01 & 1991 & 10 & $2.000,00$ & 200,00 & 17 & 0 \\
\hline Desentregador & & 01 & 1990 & 10 & 500,00 & 50,00 & 18 & 0 \\
\hline Adubadeira & & 01 & 1985 & 10 & 500,00 & 50,00 & 24 & 0 \\
\hline Roda d'água & & 01 & 2007 & 20 & $1.300,00$ & 130,00 & 02 & 58,50 \\
\hline Total & & & & & $\mathbf{1 0 9 . 3 0 0 , 0 0}$ & & & $\mathbf{5 . 7 2 8 , 5 0}$ \\
\hline $\begin{array}{c}\text { Remuneração } \\
\text { do Capital }\end{array}$ & & & & & $\mathbf{6 . 5 5 8 , 0 0}$ & & & \\
\hline
\end{tabular}

Fonte: Dados da Pesquisa

Quadro 3 - Depreciação dos animais da Fazenda Rosário, no período de 08 de Agosto de 2008 a 30 de Abril de 2009

\begin{tabular}{|c|c|c|c|c|c|c|c|}
\hline Especificação & Quant. & $\begin{array}{c}\text { Vida } \\
\text { Útil }\end{array}$ & $\begin{array}{c}\text { Valor } \\
\text { Atual }\end{array}$ & $\begin{array}{c}\text { Valor } \\
\text { Atual } \\
\text { Total }\end{array}$ & $\begin{array}{c}\text { Valor } \\
\text { Residua } \\
\text { I }\end{array}$ & $\begin{array}{c}\text { Depreciaçã } \\
\text { o anual }\end{array}$ & $\begin{array}{c}\text { Depreciaçã } \\
\text { o Total }\end{array}$ \\
\hline Vacas & 27 & 8 & $1.500,00$ & $40.500,00$ & 150,00 & 168,75 & $4.556,25$ \\
\hline Bois & 01 & 8 & $1.500,00$ & $1.500,00$ & 150,00 & 168,75 & 168,75 \\
\hline Total & & & & $\mathbf{4 2 . 0 0 0 , 0 0}$ & & & $\mathbf{4 . 7 2 5 , 0 0}$ \\
\hline $\begin{array}{c}\text { Remuneraçã } \\
\text { o do Capital }\end{array}$ & & & & $\mathbf{2 . 5 2 0 , 0 0}$ & & & \\
\hline
\end{tabular}

Fonte: Dados da Pesquisa 
CINQUINI FILHO, J. et al. Desempenho econômico do sistema de produção de cria, recria e engorda em bovinos de corte da Fazenda Rosário, Ituiutaba-MG. PUBVET, Londrina, V. 5, N. 9, Ed. 156, Art. 1056, 2011.

\section{Planilhas de Custos}

Quadro 4 - Custos totais e unitários da Fazenda Rosário, no período de 08 de Agosto de 2008 a 30 de Abril de 2009

\begin{tabular}{|c|c|c|c|}
\hline Especificação & $\begin{array}{l}\text { Valor } \\
\text { Total }\end{array}$ & $\begin{array}{c}\text { Valor } \\
\text { Unitário }\end{array}$ & $\begin{array}{c}\% \\
\text { Custo }\end{array}$ \\
\hline \multicolumn{4}{|l|}{ 1. Custo de produção } \\
\hline 1.1 Custo Variável & $41.259,74$ & 371,59 & 44,61 \\
\hline 1.1.1 Custo Operacional Variável & $40.058,00$ & 360,76 & $\underline{43,31}$ \\
\hline Insumos & $12.178,00$ & 109,71 & 13.17 \\
\hline Nutrição & $8.198,00$ & 73,89 & 8,87 \\
\hline Medicamentos & $3.980,00$ & 35,82 & 4,30 \\
\hline Serviços & $27.880,00$ & 251,15 & 30,15 \\
\hline Mão-de-obra Temporária & 900,00 & 8,08 & 0,97 \\
\hline Manutenção de Máquinas & 250,00 & 2,33 & 0,28 \\
\hline Manutenção de equipamentos & 200,00 & 1,75 & 0,21 \\
\hline Telefone & 450,00 & 4,08 & 0,49 \\
\hline Gasolina & 880,00 & 7,91 & 0,95 \\
\hline Diesel & 800,00 & 7,17 & 0,86 \\
\hline Manutenção de pastagens & $20.000,00$ & 180,18 & 21,63 \\
\hline Fretes & $4.400,00$ & 39,65 & 4,76 \\
\hline 1.1.2 Custo Alternativo Variável & $1.201,74$ & 10,83 & 1,30 \\
\hline Remuneração do capital circulante & $1.201,74$ & 10,83 & 1,30 \\
\hline 1.2 Custo Fixo & $\underline{51.213,83}$ & 461,38 & $\underline{55,39}$ \\
\hline 1.2.1 Custo Operacional Fixo & $\mathbf{1 5 . 9 5 3 , 8 3}$ & 143,77 & 17,26 \\
\hline Impostos, Taxas e outros & 700,00 & 6,33 & 0,76 \\
\hline Depreciação das Benfeitorias & $4.800,33$ & 43,31 & 5,20 \\
\hline Depreciação de Máq e equip. & $5.728,50$ & 51,65 & 6,20 \\
\hline Depreciação dos Animais & $4.725,00$ & 42,48 & 5,10 \\
\hline 1.2.2 Custo Alternativo Fixo & $35.260,00$ & 317,61 & 38,13 \\
\hline Remuneração da terra & $10.600,00$ & 95,46 & 11,46 \\
\hline Remuneração do capital & $24.660,00$ & 222,15 & 26,67 \\
\hline 1.3 Custo Total de Produção & $92.473,57$ & 832,97 & 100,00 \\
\hline 1.3.1 Custo Operacional Total & $56.011,83$ & 504,54 & 60,57 \\
\hline 1.3.2 Custo Alternativo Total & $36.461,74$ & 328,43 & 39,43 \\
\hline
\end{tabular}

Fonte: Dados de Pesquisa 
CINQUINI FILHO, J. et al. Desempenho econômico do sistema de produção de cria, recria e engorda em bovinos de corte da Fazenda Rosário, Ituiutaba-MG. PUBVET, Londrina, V. 5, N. 9, Ed. 156, Art. 1056, 2011.

Quadro 5 - Apuração de resultados da Fazenda Rosário, no período de 08 de Agosto de 2008 a 30 de Abril de 2009

\begin{tabular}{|l|r|c|c|}
\hline \multicolumn{1}{|c|}{ Especificação } & $\begin{array}{c}\text { Valor Total } \\
(\mathrm{R} \$)\end{array}$ & $\begin{array}{c}\text { Valor Unitário } \\
(\mathrm{R} \$)\end{array}$ & $\%$ \\
\hline Renda Bruta & $\mathbf{1 5 9 . 1 9 4 , 0 0}$ & $\mathbf{1 . 4 3 4 , 1 9}$ & $\mathbf{1 0 0}$ \\
\hline Custo Total & $92.473,57$ & 832,97 & 58,08 \\
\hline Custo Operacional & $56.011,83$ & 504,54 & 35,18 \\
\hline $\begin{array}{l}\text { Renda Liquida (Renda } \\
\text { Bruta - Custo Operacional } \\
\text { total) }\end{array}$ & $103.182,17$ & 929,50 & 64,81 \\
\hline $\begin{array}{l}\text { Lucro (Renda Bruta -Custo } \\
\text { Total) }\end{array}$ & $66.720,43$ & 601,07 & 41,91 \\
\hline
\end{tabular}

Fonte: Dados de Pesquisa

\section{Cálculo do ponto de nivelamento e sua representação gráfica}

Com base na planilha de custo temos:

$\mathrm{CFT}=\mathrm{R} \$ 51.213,83$

$\mathrm{Pu}=\mathrm{R} \$ 1434,19$

$\mathrm{CVTu}=\mathrm{R} \$ 371,59$

$\mathrm{PN}=51.213,83 /(1.434,19-371,59)$

$\mathrm{PN}=48,20$ Animais 
CINQUINI FILHO, J. et al. Desempenho econômico do sistema de produção de cria, recria e engorda em bovinos de corte da Fazenda Rosário, Ituiutaba-MG. PUBVET, Londrina, V. 5, N. 9, Ed. 156, Art. 1056, 2011.

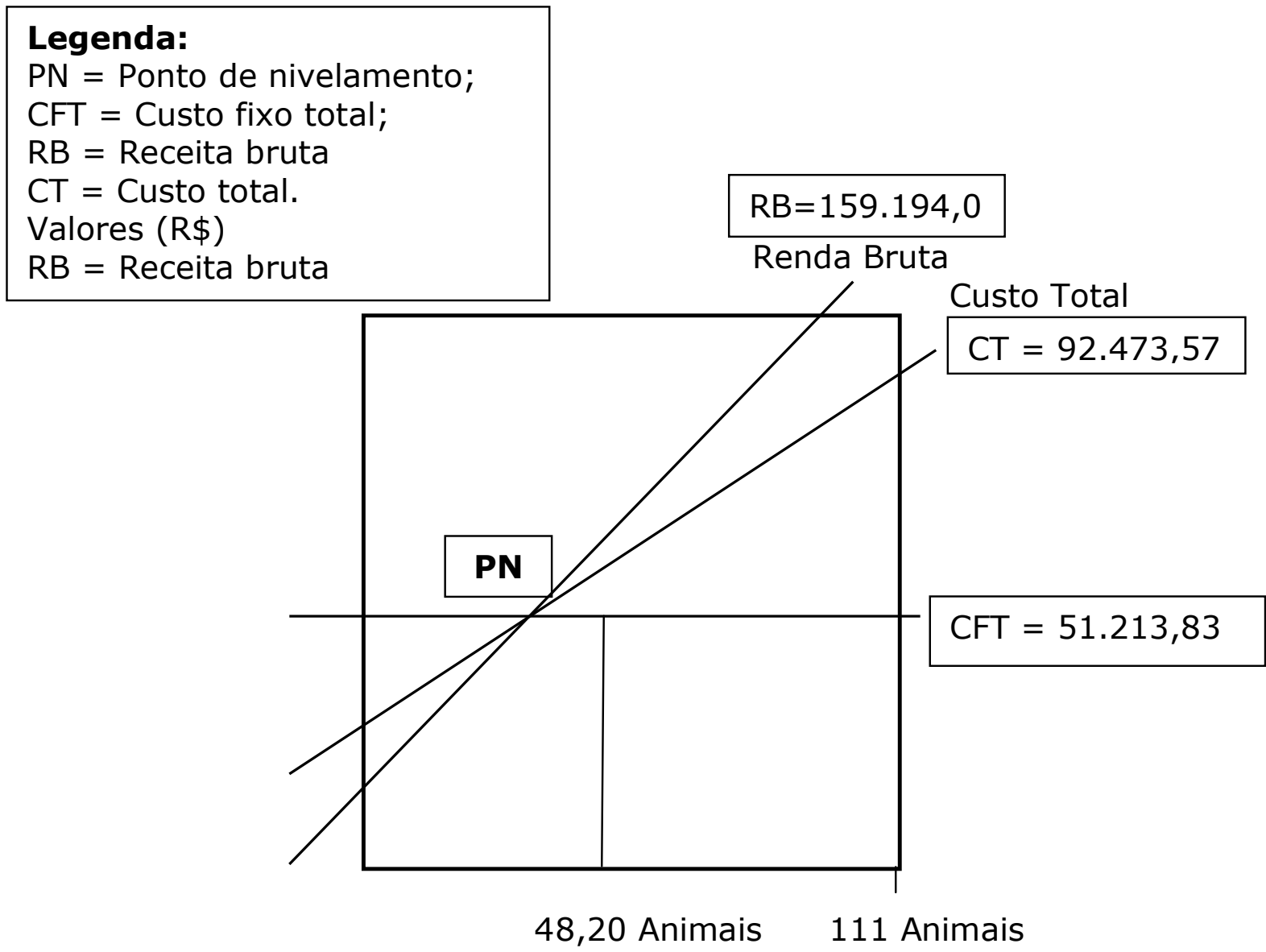

Figura 1: Representação gráfica do Ponto de Nivelamento (PN) 
CINQUINI FILHO, J. et al. Desempenho econômico do sistema de produção de cria, recria e engorda em bovinos de corte da Fazenda Rosário, Ituiutaba-MG. PUBVET, Londrina, V. 5, N. 9, Ed. 156, Art. 1056, 2011.

\section{Análise de rentabilidade}

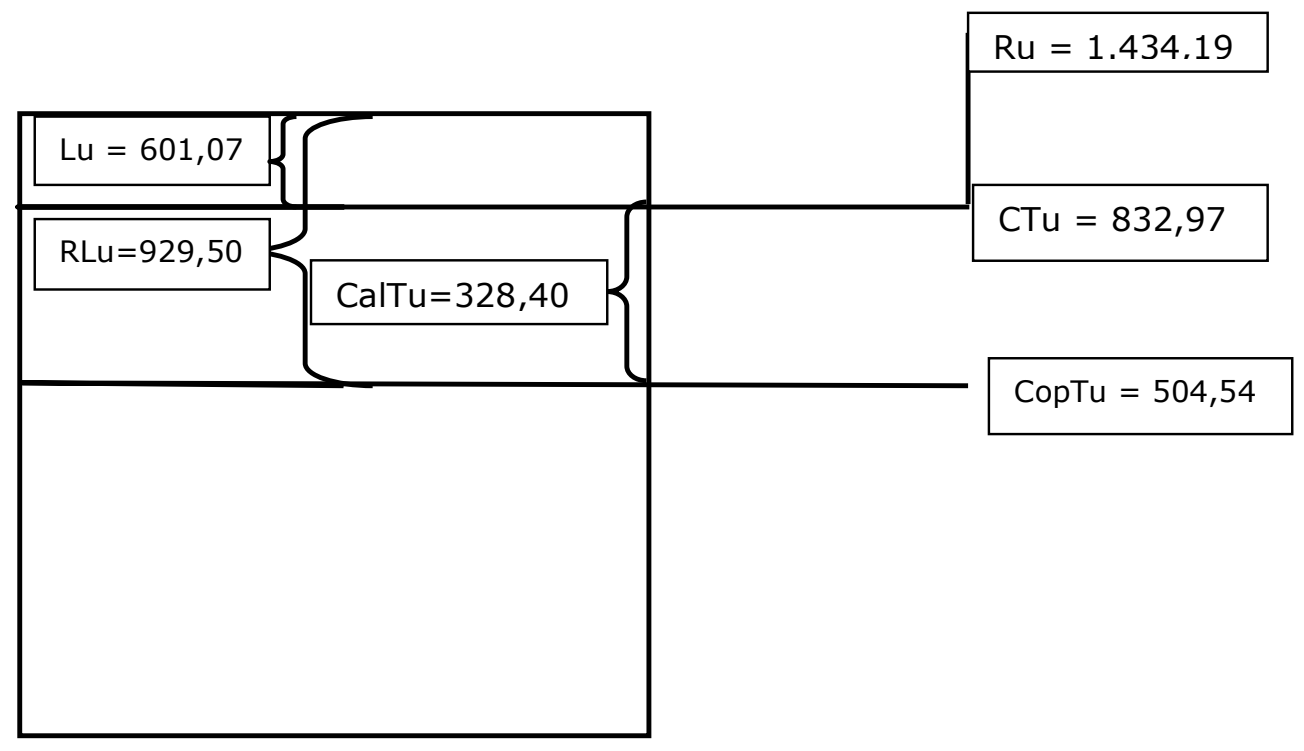

Legenda:

CTu = Custo total unitário;

$\mathbf{R u}=$ Renda unitária;

CopTu = Custo operacional total unitário;

CalTu = Custo alternativo total unitário;

Lu = Lucro unitário;

$\mathbf{R L u}=$ Receita liquida unitária.

Valores $(R \$)$

Lu = Lucro unitário; Rlu = Receita liquida unitária.

Figura 2: Representação gráfica da análise de rentabilidade.

\section{Indicadores de resultado econômico}

\section{Lucratividade}

Lucratividade $=\{(159.194,00-92.473,57) \times 100\} / 159.194,00$

Lucratividade $=41,91 \%$ 
CINQUINI FILHO, J. et al. Desempenho econômico do sistema de produção de cria, recria e engorda em bovinos de corte da Fazenda Rosário, Ituiutaba-MG. PUBVET, Londrina, V. 5, N. 9, Ed. 156, Art. 1056, 2011.

\section{Rentabilidade}

Rentabilidade sobre o capital $=(66.720,43 / 1.045 .000,00) \times 100$

Rentabilidade sobre o capital $=6.38 \%$

\section{Capacidade de Investimento}

Capacidade de Investimento $=159.194,00-56.011,83$

Capacidade de Investimento $=\mathrm{R} \$ 103.182,17$

\section{Índice de capacidade de investimento}

Índice de capacidade de investimento $=(103.182,17 / 159.194,00) \times 100$

Índice de capacidade de investimento $=64,81 \%$

Tabela 7 - Análise de alguns indicadores de resultados econômicos da Fazenda Rosário, no período de 08 de Agosto de 2008 a 30 de Abril de 2009

\begin{tabular}{ll}
\hline Indicador & Valor \\
\hline & \\
Lucratividade & $41,91 \%$ \\
Rentabilidade sobre o capital & $6,38 \%$ \\
Índice de capacidade de investimento & $64,81 \%$ \\
\hline
\end{tabular}

Fonte: Dados de Pesquisa

\section{Discussão}

Como podemos notar os serviços representam 30,15\% dos custos de produção sendo destes 29,18\% representados por serviços contratados e 0,97\% representados por mão-de-obra temporária. Outro grande representante dos custos de produção são os custos alternativos fixos com $38,13 \%$, sendo representado pela remuneração da terra no valor de $11,46 \%$ e a remuneração do capital no valor de $26,67 \%$. 
CINQUINI FILHO, J. et al. Desempenho econômico do sistema de produção de cria, recria e engorda em bovinos de corte da Fazenda Rosário, Ituiutaba-MG. PUBVET, Londrina, V. 5, N. 9, Ed. 156, Art. 1056, 2011.

A análise do desempenho econômico da fazenda Rosário mostra que o lucro por animal produzido foi de $\mathrm{R} \$ 601,07$, para uma receita unitária de $\mathrm{R} \$$ $1.434,19$ por animal produzido e um custo total unitário de $\mathrm{R} \$ 832,97$.

A lucratividade no período analisado foi de $41,91 \%$ mostrando que o produtor esta tendo um custo menor do que sua receita e a rentabilidade sobre o capital foi de $6,38 \%$.

O índice de capacidade de investimento da atividade foi de $64,81 \%$, esse valor o que sobra após o pagamento de todos os desembolsos efetuados e reposição das depreciações, e que pode ser investido na propriedade.

Tanto a remuneração da terra bem como a de capital são fatores importantes que elevam o valor dos custos fixos em geral.

A implementação da escrituração zootécnica esta sendo importante para a propriedade, pois viabilizará em breve a análise de alguns índices produtivos e reprodutivos importantes para o crescimento da atividade, da mesma forma que a escrituração financeira fará com que o produtor saiba onde estão os pontos de estrangulamento de sua produção e possa cortar custos, e até melhorar os investimentos na propriedade.

\section{Conclusão}

A propriedade obteve lucro durante o período de análise no valor de $\mathrm{R} \$$ $66.720,43$.

Nas condições da presente análise a atividade apresentou-se viável, pois cobriu todos os custos operacionais e alternativos e, ainda, proporcionou uma rentabilidade de $6,38 \%$ do valor de capital aplicado na mesma.

\section{Referências}

ARAUJO, F. R. C. Avaliação do desempenho reprodutivo de um rebanho da raça nelore da região do triângulo mineiro, 1994. 30f. Monografia (Graduação) - Faculdade de Medicina Veterinária, Universidade Federal de Uberlândia, Uberlândia, 1994.

ALVES, S. J.; MORAES, A. Algumas considerações sobre a Intensificação da bovinocultura em áreas de pastagens. Disponível em : www. fundepecpr. org.br/ tev/ palestras /palestra09.doc. Acesso em: 27 de set. 2008. 
CINQUINI FILHO, J. et al. Desempenho econômico do sistema de produção de cria, recria e engorda em bovinos de corte da Fazenda Rosário, Ituiutaba-MG. PUBVET, Londrina, V. 5, N. 9, Ed. 156, Art. 1056, 2011.

ANTUNES, L. M., ANGEL, A. Custos de produção Manual de administração rural, 3 ed. Guaíba: Agropecuária, 1999.

BORGeS, I., BARBOSA, F.A., ALBUQUeRQUE, F.H.M.A.R. Planejamento e gestão de sistemas de produção. In: Anais IV Simpósio Mineiro de Ovinocultura,UFLA . Lavras, 2005, p. 1-29.

FIGUEIREDO, R. S. Sistemas de apuração de custos. In: BATALHA, O. M. (Coord.) Gestão Agroindustrial. V1. São Paulo: Atlas, 1997.

HOFFMANN, R.; SERRANO, O.; Neves, E.M. el al. Administração da empresa agrícola, 6 ed. São Paulo: Pioneira, 1989

IEL, SEBRAE, CNA. Estudo sobre a eficiência econômica e competitividade da cadeia agroindustrial da pecuária de corte no Brasil. 2000. Disponível em: http://www.cna.org.br/PublicacoesCNA/EstudosdasCadeiasProdutivas/Pecuaria de corte. Acesso em: 18 de abril de 2009.

JANK, F. S. Importância da administração profissional da produção agropecuária. Preços Agricolas. Piracicaba, Nov., 1997.

LAZZARINI, S . N ; Lucrando com a pecuária - cria e recria 3 ed . Viçosa - MG ; Aprenda Fácil 2003. p $88,89$.

LÔBO, R. N. B. A importância da escrituração zootécnica na caprino-ovinocultura. Disponível em: < http://www.cnpc.embrapa.br/genecoc/escrit.htm>. Acesso em: 21 abril de 2009.

MARION, José C., SANTOS, Gilberto J. Administração de Custos na Agropecuária. $2^{\mathrm{a}}$ ed. SP: Atlas, 1996.

MATSUnAGA, M. ; Bemelmans, P. F. ; TOLEDO, P. E. N. de et al. Metodologia de custo de produção utilizada pelo IEA. Agricultura em São Paulo, ano XXIII, tomo 12, 1976.

PIRTOUSCHeg, A. Custos de Produção na Agropecuária e Planejamento Rural, Uberlândia: Universidade Federal de Uberlândia, 1999.

PIRTOUSCHEG, A. ; MACHADO, T. M. M. Análise econômica da produção de leite de cabra. Uberlândia: Universidade Federal de Uberlândia, 1990.

POLAQUINI, L. E. M.; SOUZA, J. G.; GEBARA' J. J. Transformações técnico-podutivas e comerciais na pecuária de corte brasileira a partir da década de 90 . Revista Brasileira de Zootecnia. Viçosa, vol.35, no.1,Jan./Feb. 2006.

REHFELD, O. A.; AZEVEDO, N. A. ; PAULinO, M. F. Controle zootécnico e eficiência da produção. Informe Agropecuário, Belo Horizonte, v. 89, n. 8, p.66-69, maio 1984.

REIS, A. J. ; GUIMARÃES, J. M. P. Custo de produção na agricultura. Informe Agropecuário. Belo Horizonte, v.12, no 143, p.15-22, Nov. 1986.

SOUZA, R.; GUIMARÃES, J. M. P.; MORAIS, V. A. et al. Administração da fazenda. Globos, 5 ed., São Paulo. 211 p. 1995. 
CINQUINI FILHO, J. et al. Desempenho econômico do sistema de produção de cria, recria e engorda em bovinos de corte da Fazenda Rosário, Ituiutaba-MG. PUBVET, Londrina, V. 5, N. 9, Ed. 156, Art. 1056, 2011.

YAMAGUCHI , L . C . T . ; CARNEIRO , A . V . Aplicação de planilha eletrônica na análise técnica e econômica de unidades de produção de leite . In : CONGRESSO, DA SOCIEDADE BRASILEIRA DE INFORMÁTICA APLICADA À AGROPECUÁRIA E À AGROINDUSTRIA , 1 , Belo Horizonte, 1997 . Anais... Belo Horizonte, 1997. p. 95 - 99. 